
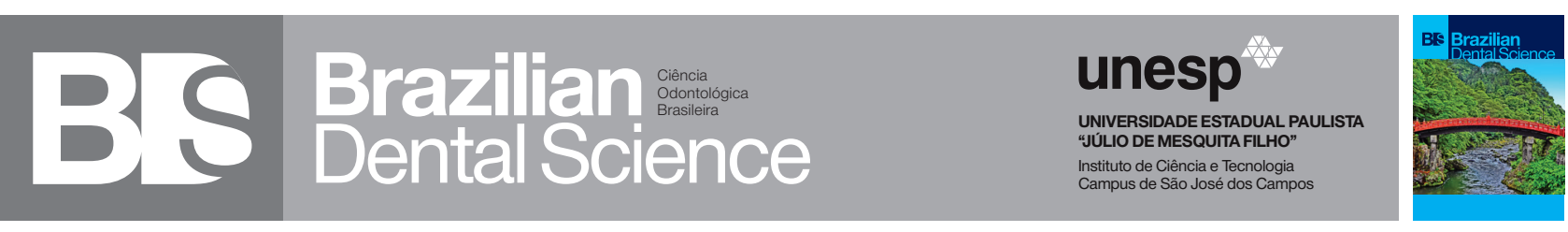

\title{
Impact of dental treatment on self-esteem and oral health self- perception of children and adolescents victims of sexual abuse
}

Impacto do tratamento odontológico na autoestima e autopercepção de saúde bucal de crianças e adolescentes vítimas de abuso sexual

Ana Luísa de Ataíde MARIZ ${ }^{1}$, Symonne Leandro ARAÚJO ${ }^{1}$, Luiz Antônio NEGRINHO ${ }^{1}$, Marlus da Silva PEDROSA², José Guilherme Férrer POMPEU ${ }^{3}$, Cláudio Heliomar Vicente da SILVA ${ }^{1}$

1 - Department of Prosthetic Dentistry and Maxillofacial Surgery - Federal University of Pernambuco - UFPE - Recife - Pernambuco - Brazil.

2 - Department of Dentistry (Biomaterials and Oral Biology) - University of São Paulo - USP - São Paulo - São Paulo - Brazil.

3 - Department of Restorative Dentistry - Federal University of Piauí - UFPI - Teresina - Piauí - Brazil.

\begin{abstract}
Objective: To evaluate the oral health selfperception and the influence of dental treatment on the self-esteem of children and adolescents victims of sexual abuse. Material and Methods: It was adopted a qualitative methodology that emphasized the deepening and comprehension of the answers obtained. Six children and adolescents, from both genders, victims of sexual abuse in the last two years, aged between 10 and 15, took part of the study. A questionnaire was applied before and after the dental treatment in order to evaluate changes in the self-perception and self-esteem of the individuals. The answers were categorized into two thematic axes with the use of the qualitative content analysis: self-perception and self-esteem. Psychological attendance prior and after the dental interventions enabled to comprehend the changes observed. Results: The participants presented a coherent self-perception in relation to the present clinical situation and an increase of their self-esteem after the dental interventions. Conclusion: Dental treatment contributed to improvements regarding self-esteem and oral health self-perception in victims of sexual abuse.
\end{abstract}

\section{KEYWORDS}

Self concept; Sex offenses; Dental esthetics; Adolescent; Child.

\section{RESUMO}

Objetivo: Analisar a autopercepção da saúde bucal e a influência do tratamento odontológico na autoestima de crianças e adolescentes vítimas de abuso sexual. Material e Métodos: Utilizou-se a metodologia para análise de conteúdo qualitativa que enfatizou o aprofundamento e a compreensão das respostas obtidas. Seis crianças e adolescentes, ambos os gêneros, vítimas de abuso sexual nos últimos dois anos, com idade entre 10 e 15 anos, participaram do estudo. Um questionário foi aplicado antes e após o tratamento odontológico para avaliar mudanças na autopercepção e na autoestima dos indivíduos. Através da análise de conteúdo, as respostas foram categorizadas em dois eixos temáticos: autopercepção e autoestima. O atendimento psicológico antes e após as intervenções odontológicas possibilitou compreender as mudanças observadas. Resultados: Os participantes deste estudo apresentaram uma autopercepção de saúde bucal coerente com a realidade clínica encontrada e que houve aumento da autoestima após as intervenções odontológicas. Conclusão: $\mathrm{O}$ tratamento odontológico contribuiu para melhorias na autoestima e autopercepção da saúde bucal das crianças e adolescentes vítimas de abuso sexual.

\section{PALAVRAS-CHAVE}

Autoimagem; Delitos sexuais; Estética dentária; Adolescente; Criança. 


\section{INTRODUCTION}

$\mathrm{V}$ iolence against children and adolescents is treated in several countries as a public health problem of high prevalence, which causes serious consequences to the psychological and social development of the victims and their families [1-4]. Other major concern is that the victims are often not assisted by qualified health services [5].

The World Health Organization [6] defined violence as "the intentional use of physical force or power, threatened or actual, against oneself, another person, or against a group or community, that either results in or has a high likelihood of resulting in injury, death, psychological harm, maldevelopment or deprivation". It can be classified into different types: physical abuse, psychological abuse, neglect or abandon and sexual abuse [7-8]. However, this classification have only a didactic objective and does not exclude the possibility of this phenomenon occurring dynamically and simultaneously [7].

Any form of abuse in childhood or adolescence is understood as an act practiced contrary to the will of the victim, capable of causing physical, psychological or sexual harm and is carried out, in most situations, by persons directly related to the victims $[9,10]$.

Several studies have shown that children and adolescents who have been sexually abused may develop anxiety disorders, depressive and aggressive symptoms, problems with their role and sexual functioning, and serious difficulties in interpersonal relationships [11,12]. Thus, the complexity of the context lived by these young people requires a multiprofessional approach [13]. Dentistry is often taken to interdisciplinary approach, however, there is an underestimation and a great difficulty of understanding the factors external to the mouth [14].
The mouth must be understood as a multiple place of meanings that are present in human culture and psychism $[15,16]$. Within this context, in general, health professionals involved in the care of adolescents should be alert to situations of violence as a triggering and aggravating factor of physical and emotional diseases, seeking effective prevention and intervention measures [11].

The concern with personal appearance has become a relevant factor in human relationships, since those who do not present themselves within these patterns, often feel excluded [17]. Thus, young victims of sexual abuse may manifest a number of psychological complications, including low self-esteem [18], in which vary due a number of factors, including the oral health condition.

The self-esteem is defined as the perception of one's own ability to effectively master or deal with the surrounding environment, and it is affected by the reactions of others towards an individual [19]. A high self-esteem may be seen as a favorable global evaluation of the self and low self-esteem as the unfavorable evaluation [20].

Oral health has a substantial effect on people's general health and well being [21]. Children and adolescents who have suffered abuse may have worse oral health status compared with those who were not victims of violence [22]. Moreover, the literature shows that several dental disorders such as malocclusion, anterior traumatic teeth, teeth loss and untreated decay causes a profound impact on aesthetics and psychosocial behaviour of adolescents, thus affecting their self-esteem [21].

Considering that the teeth are important for psychological and social well-being [22], as well as the need for the disciplinary integration to improve the care for young victims of sexual abuse, this study aimed to evaluate the selfperception of oral health, as well as the influence 
of dental treatment on the improvement of the self-esteem of this population.

\section{MATERIAL AND METHODS}

The Research Ethics Committee of the Integrated Health Center Hospital Amaury de Medeiros of the University of Pernambuco approved this research (Approval number: 040/08).

It was carried out a qualitative research based on a content analysis methodology with convenience sampling of six children and adolescents, 10 to 15 years-old, both genders, victims of sexual abuse, assisted in the Dom Hélder Câmara Center (CENDHEC), Recife, Pernambuco, Brazil. The inclusion criteria was the presence of dental problems, especially those of aesthetic interference that had a direct influence on self-esteem.

A protocol for immediate care, adopted by the health and social care team, was completed and the adolescents' approach was carried out based on the opinion of the psychologist regarding the appropriate time to start dental interventions.

After signing a free informed consent form, the individuals were individually interviewed according to a questionnaire based on the studies of Unfer and Saliba [24] to obtain information on the level of knowledge regarding oral health care.

The oral health self-perception and the relationship of dental treatment in the multidisciplinary rehabilitation of adolescents victims of sexual violence were evaluated through the application of a questionnaire that sought to analyze some aspects related to the physical and emotional well-being before and after the improvement of the oral health condition. To do so, the questions (Chart 1) were recorded through a recorder (Panasonic / RQ-L31).
The information regarding the act of violence practiced was collected from the medical record, not being commented on, nor even questioned to the adolescent during the research. Dental treatment was started soon after the application of the initial questionnaire.

In the first session, the following procedures were performed: Anamnesis; Dental clinical examination; Application of the plaque control record [25]; Oral hygiene instructions; Prophylaxis; Initial photographic of the oral condition; And four interproximal radiographs of premolars and molars (when necessary, periapical radiographs were performed). The treatment plan was elaborated and depending on the complexity of the treatment, the sessions were carried out until the conclusion of the dental treatment.

The individuals showed a special interest in tooth whitening. In some situations, aesthetic restorative procedures were performed for diastema closure and restoration of incisal edges.

The dental treatment was dependent on the need and the characteristics of each adolescent, being carried out according to the priorities: 1: Oral environment stabilization (Removal of biofilm retentive factors basic periodontal procedures - endodontic treatment); 2: Tooth whitening; 3: Aesthetic restorative procedures;

At the end of each treatment, photographic of the patients' oral condition was performed and the psychologist carried out a new evaluation of the patients in order to make possible the comparison with the previous psychological analyzes, aiding in the interpretation of the answers. After 30 days of dental treatment, the oral health selfperception questionnaire was again applied.

Personal and social-demographic data were tabulated and the others were qualitatively analyzed by content analysis. 
This qualitative data analysis methodology consists of disassembling the structure and elements of the content to clarify its different characteristics and extract its meaning [26]. Thus, it was sought to understand the speech of the interviewees, contemplating the manifest and implicit content, present in the answers, ordering and categorizing the data for final analysis, with a view to understanding the object of study.

\section{RESULTS}

Six children and adolescents, 10 to 15 years-old, being 03 male and 03 female, were evaluated. Only one male in the sample did not go to school. All the others studied in elementary public schools. Although those responsible for the children and adolescents presented a remunerated activity, they considered the monthly family income insufficient.

The degree of knowledge about aspects of dental interest showed little knowledge on the problems that can affect oral health, as well as on prevention and control measures that can be adopted as means of recovery and maintenance of oral health conditions.

The clinical examination showed a very variable dental condition. No participant had good oral hygiene conditions and flossing was rarely performed. The plaque index showed that on average the adolescents presented $65.5 \%$ of the smooth surfaces of their teeth stained. However, despite the unfavorable conditions of biofilm control, the need for treatment of each young was varied. Not all cases required restorative intervention.

The data collected by the questionnaires applied (before and after the dental treatment) were classified into two thematic axes with the use of the qualitative content analysis: selfperception and self-esteem (Tables 2 and 3). The oral health self-perception did not show distortion in relation to the reality presented to the clinical examination. Although they were not able to express, in all cases, exactly presented problems, they were aware of their situation.

Only the subject "A" demonstrated distorted knowledge regarding his oral health, believing that he was in poor oral condition, when in fact he did not need treatment except for biofilm control (Table 2).

Regarding the thematic axis 2, the speeches obtained showed improved self-esteem after the dental treatments. It was possible to observe that, at the beginning of the study, no adolescent felt satisfied with the conditions of his smile, which was reversed after the dental appointments. This change also provided, for some participants, a greater socialization and appreciation of the importance of maintaining a good oral health condition and consequently of the smile (Table 3 ).

Table 1 - Dental procedures performed

\begin{tabular}{|ccccccc|}
\hline & A & B & C & D & E & F \\
\hline $\begin{array}{c}\text { Tooth Extraction/ } \\
\text { Removal of root tip }\end{array}$ & & 1 & & 1 & \\
\hline $\begin{array}{c}\text { Periodontal basic } \\
\text { procedures }\end{array}$ & 1 & 1 & 1 & 1 & 1 & 1 \\
\hline Endodontic treatment & & 1 & & & & \\
\hline Tooth whitening & 1 & 1 & & 1 & & \\
\hline Aesthetic restorations & & 3 & 5 & & 2 & 11 \\
\hline Periodontal plastic surgery & 1 & & & & \\
\hline
\end{tabular}


Table 2 - Results obtained regarding of self-perception of the oral health condition

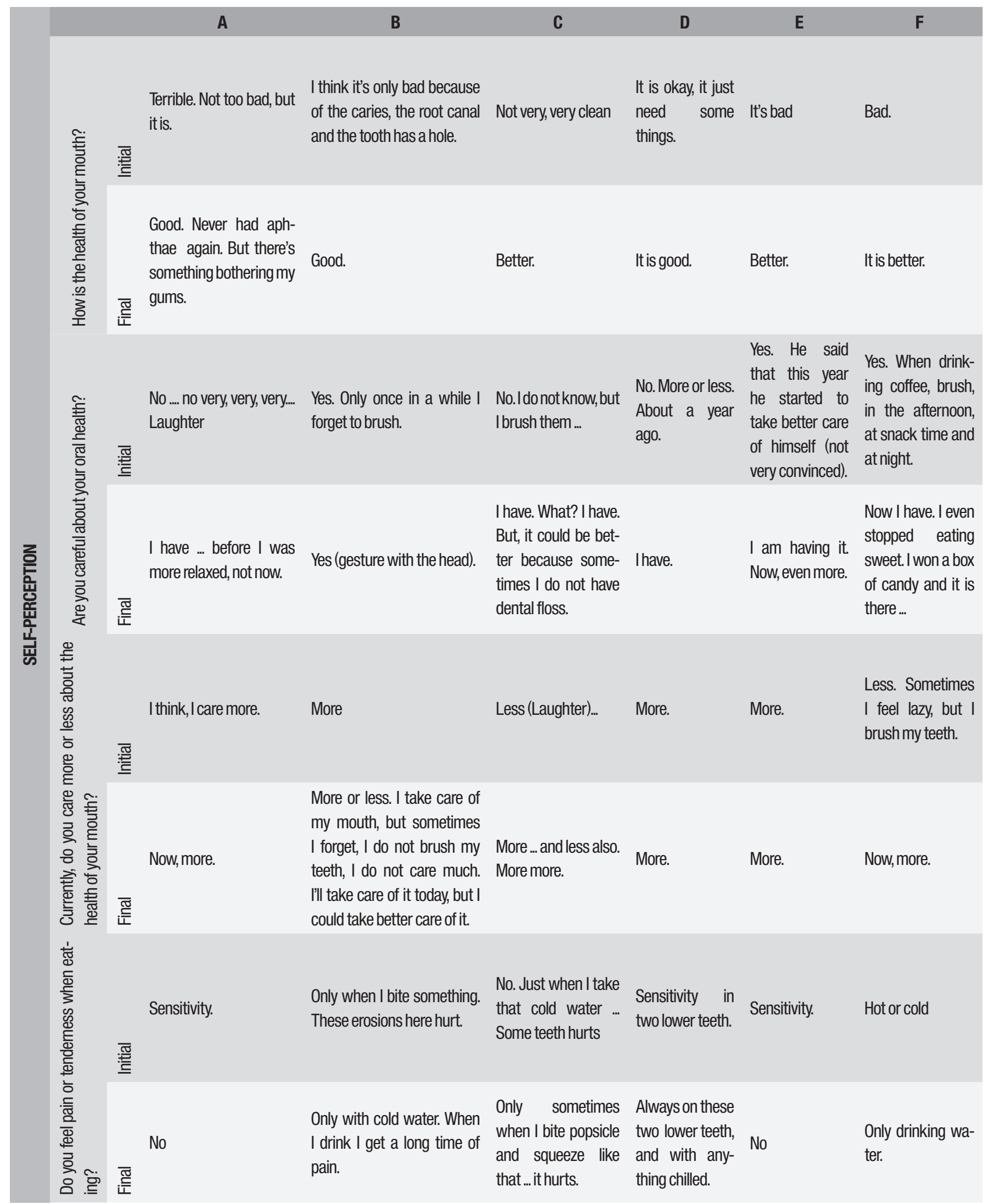

Initial - before the dental treatment; Final - after the dental treatment. 
Table 3 - Results obtained in the smile-related self-esteem

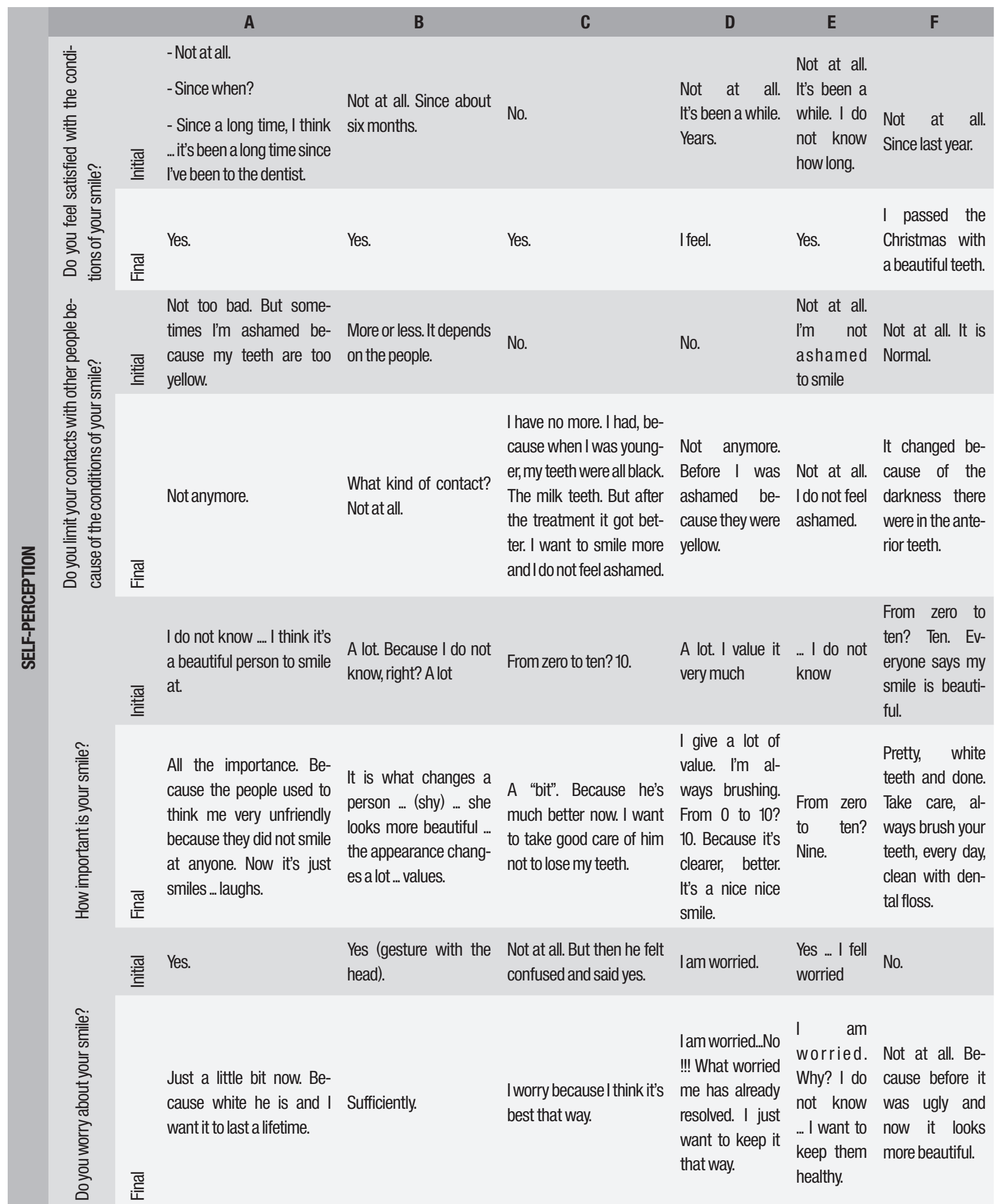

Initial - before the dental treatment; Final - after the dental treatment. 


\section{DISCUSSION}

The self-perception of the need for treatment reflects, in part, the impact that a disease has on the individuals, showing the degree of deficiencies and dysfunctions arising from the health condition, as well as the perceptions and attitudes of the individuals in this regard [21,27,28]. Thus, assessing selfperception of oral health within a population is important given that health is defined as "a dynamic state of complete physical, mental, spiritual, and social well-being and not just the absence of disease or infirmity" [29].

In this sense, questions related to self-perception and self-esteem were used, presenting an objective and mainly subjective character, since it was intended to observe the expressed needs of the participants in order to overcome the strictly objective evaluation of clinical practice that often makes impossible results related to the improvement of quality of life.

The experience of sexual abuse can affect the development of children and adolescents in various ways, with frequent depression, anxiety, low self-esteem and social isolation [1-3, 8-12]. Therefore, it is important to know the emotional state of these victims, as well as to understand the real needs they present for the establishment of the best therapeutic behavior capable of helping to improve their quality of life.

The results found in the self-perception thematic axis evidenced that the majority of the participants demonstrated coherence regarding the perception of their oral health condition. This fact becomes clear from the answers obtained regarding the question "How is your oral the health?": "I think it is only bad because of the caries, the root canal and the tooth to restore" - participant B; "Very, very clean no" -adolescent C; "Okay, just need some improvements" - participant D; "Too bad" - participant E; "Bad” - Adolescent F (Table 2).

Although most of the participant did not explain exactly the problem that affected them, the clinical condition found in each situation showed a compatible picture to that presented in the responses (Figure 1). Only the participant " $\mathrm{A}$ " demonstrated distortion in the perception of his oral health condition when it was answered that the oral health was bad, when in fact participant did not present any related disease, requiring only biofilm control (Figure 1). 
Figure 1 - Initial clinical and radiographic aspects of the participants' dentition

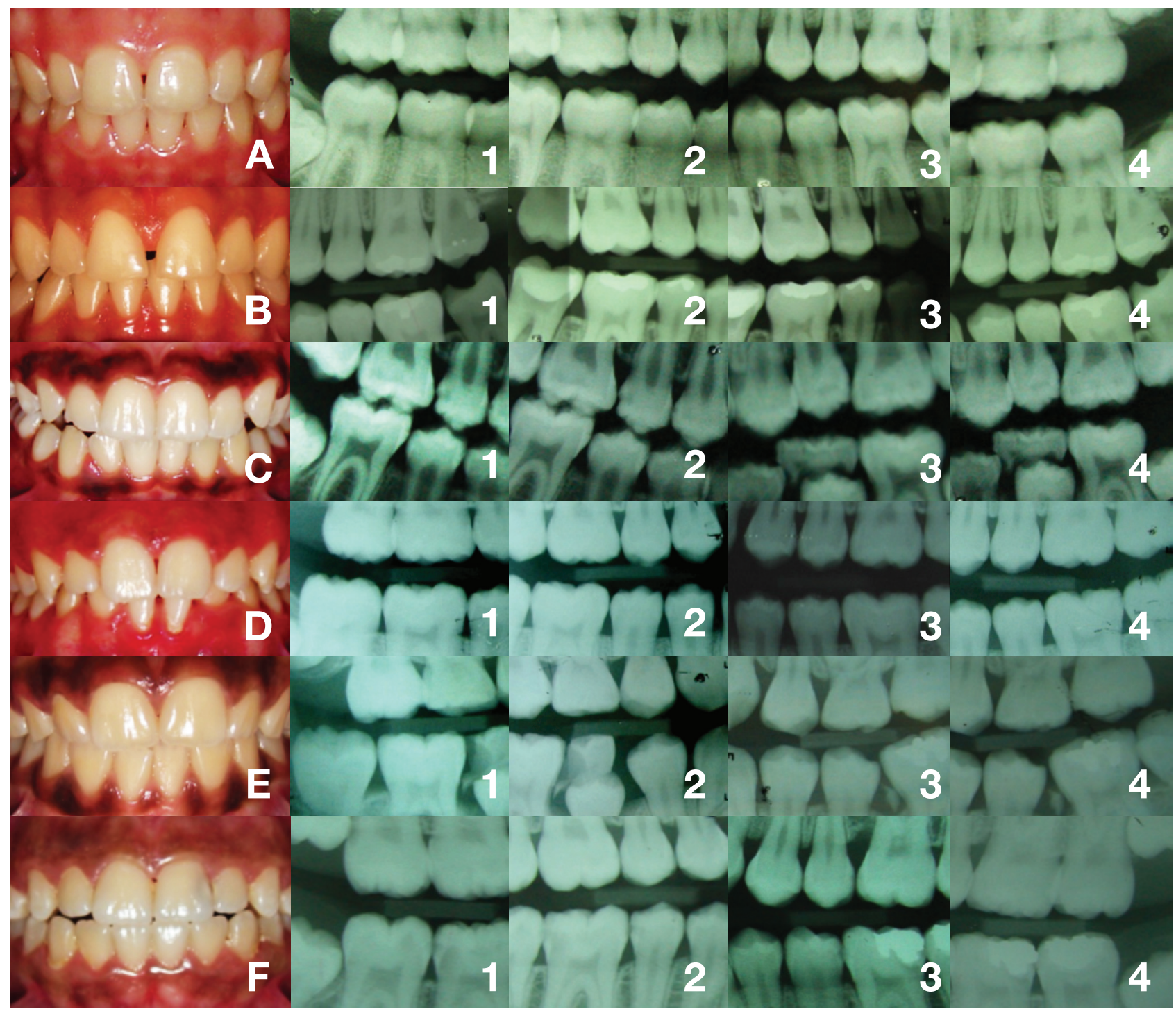

A-F: Denomination of participants; 1 - Interproximal radiograph of left molars; 2 - Interproximal radiograph of left premolars; 3 Interproximal radiograph of right molars; 4 - Interproximal radiograph of right premolars. 
Regarding the perception of the degree of care related to oral health, the answers highlighted different observations, since only half of the participants reported being careful about their oral health. The others stated that they had little care and felt insecure in answering this question (Table 2).

With the course of the treatment, it was possible to observe a significant change in the responses obtained. The perception of the issues raised remained consistent with the present clinical situation, however, after the dental interventions, the participants began to present a more active and confident attitude during the interviews.

It is well-known that this fact in the answer of the participant $C$ when again questioned about his oral health condition responds "pretty better" and in the answers obtained to the question "Do you take care of your oral health?": "I have ... before... it was more relaxed, not now"- participant A; "I have" - participant D; "I'm having it. Now, even more"participant E (Table 2).

This observed change can be explained by the fact that the participant have come to have more confidence to their convictions from the moment they received professional guidance and, above all, information regarding the necessary care for the establishment of a favorable dental condition. The literature shows that effective changes in self-care can be observed when educational methods in oral health are used [30-31].

It was not mentioned any question to the act of sexual violence, which made it difficult to analyze the influence of this trauma on the perception of oral health. In the answer obtained the question "Do you care more or less of the health of your mouth today?", It was observed that only participants $\mathrm{C}$ and $\mathrm{F}$ reported taking less care of oral health at the time before dental treatment (Table 2). However, although there is a possibility of sexual abuse influencing the lack of motivation with personal care, it is difficult to state conclusively this correlation, since there was no analysis of self-perception before the fact occurred.

Finally, the interpretation that the self-perception of the participants is quite coherent becomes even clearer in the answers obtained to the last question that presents an objective character, helping this analysis more consistently. Thus, when asked about food pain or sensitivity, most of the young people answered this question in a coherent way to the present reality (Table 2). As an example of this, it was observed in the speech of the participant D, "Sensitivity in the two lower teeth", because it had areas of gingival retraction in tooth \#31 and \#41 that justified the presented sensitivity.

Thus, when asked about pain or sensitivity, most of the participant answered this question in a coherent way to the present reality (Table 2). As an example of this, it was observed in the speech of the participant D, "Sensitivity in the two of low", because it had areas of gingival retraction in tooth 31 and 41 that justified the presented sensitivity.

The study of thematic axis 2 revealed an improvement in the self-esteem. This analysis was carried out from the observation of the answers obtained to the questions related to the smile. The smile represents the expression resulting from feelings and emotions, and consequently associated with self-esteem. Moreover, self perceived satisfaction of dental esthetics has positive impact on person's social and psychological behavior and dental self confidence [32]

In this study, it was possible to observe an improvement in the satisfaction of the smile conditions. When questioned about this situation before the dental treatment, all the participants answered that they were not satisfied with the conditions of their smile. 
However, after the conclusion of the treatment, all of them changed their minds as shown in table 2. The psychological follow-up highlights this change, since some participants began to present a distinct behavior probably resulting from the improvement in the self- esteem that also aided the development of the psychotherapeutic treatment (Table 4). It was shown that the placement of a restoration, which improves dental appearance, results in a positive effect on a patient's self-esteem and quality of life [33].

Table 4 - Evolution of the psychological follow-up of the adolescents

\section{PSYCHOLOGICALEVALUATIONS}

Initial

A

Final

Initial

B

Final

Initial

C

Final There was improvement in self-esteem; He began to take more care of his body and better perception with his general health. not eat well and had difficulty seeking dental care because of the history of sexual abuse. Feeling of guilt associated.

She losther fear of dental care, showed behavioral changes, began to dress more, dress better; Started to feel more self-confident. He began to seek internship and returned to eating well.

He arrived very shy, showing a visible lack of affection and revolt for the sexual abuse. The young man often complains of pain in his body to get the attention of the mother. Victim of sexual exploitation, presenting difficulties to work on sexuality. Feeling of guilt associated.

There was an improvement in communication, he made some confidences and he was more smiling and social. He mentioned that after the dental treatmenthe started to feel like caring more. At the end, he showed a visible improvement in self-esteem.

Difficulties in socialization and shyness. He did not smile and always spoke with his head down because he was ashamed of the fact. Feeling of guilt associated.

Very depressive initial state; Made several suicide attempts due to the violence suffered, had a general state of health compromised because he did

Initially, I was very shy and inhibited due to the sexual abuse. He was very traumatized because of the organic consequences, but he showed a lot of will to recover. She felt guilty and was ashamed to smile because her teeth were yellow. Feeling of guilt associated.

D

Final He improved a lot with regard to the feeling of guilt he presented and became more communicative. The teenager reported being more social at school. The psychologist observed improvement in self-esteem and communication.

She was emotionally weak and disgusted with her body. Deficit in school and much difficulty of socialization. Victim of several episodes of sexual abuse for 1year. Feeling of guilt associated.

$E$

Elevation of self-esteem and evolution in school performance. He started to smile more because he is happier. He reported that he liked dental treatment, evidencing an improvement in his communication, which allowed him to see greater social inclusion.

Victim of sexual violence since the 9 years of age with great repercussions on their sexuality. She stopped studying, always talks with her head down Initial and is ashamed to smile because of her teeth, which makes it difficult to accept her appearance; So always wear your hair in the front. Feeling of guilt associated with the occurrence. being very happy with dental care and showed great progress in socialization, which helped her, even in legal hearings. 
During the study, positive changes related to the socialization aspect were also observed. This fact became clear in the speech of the participants A, B, and D when they stated no longer limiting their contacts with others because of the conditions of their smile (Table 3). Both participants A and D explicitly stated that they were sometimes ashamed to smile because of their yellow teeth (Figure 1).
As the bleaching treatment progressed (Figures 2 - 4), the participants began to feel more confident about their appearance, while at the same time being more motivated in relation to other aspects of their life. According to the reports of the responsible psychologist, both participants showed signs of socialization since they improved their communication, as well as attracted more interest in seeking internships that would aid in their professional formation.

Figure 2 - Evolution of the bleaching treatment of the participant A.

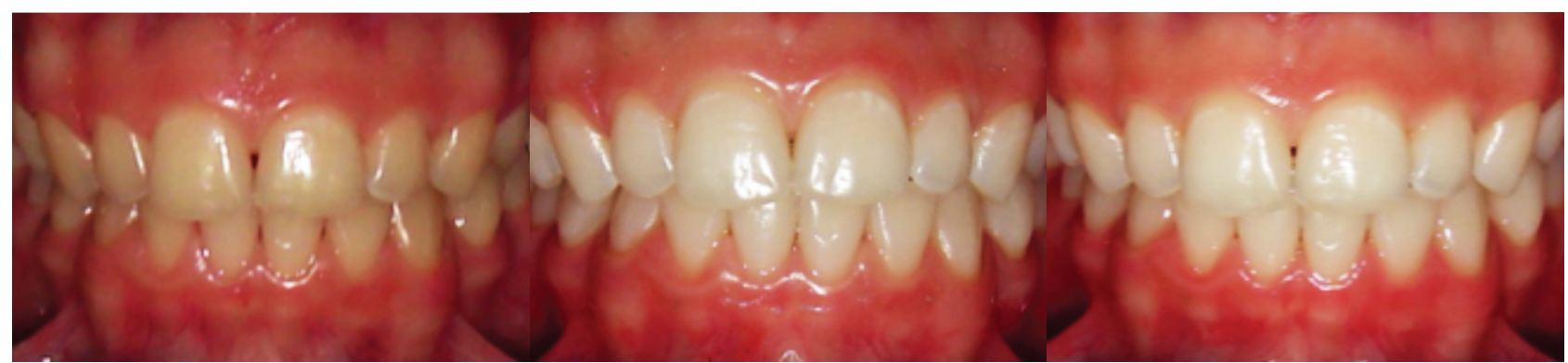

Figure 3 - Evolution of the treatment of participant B.

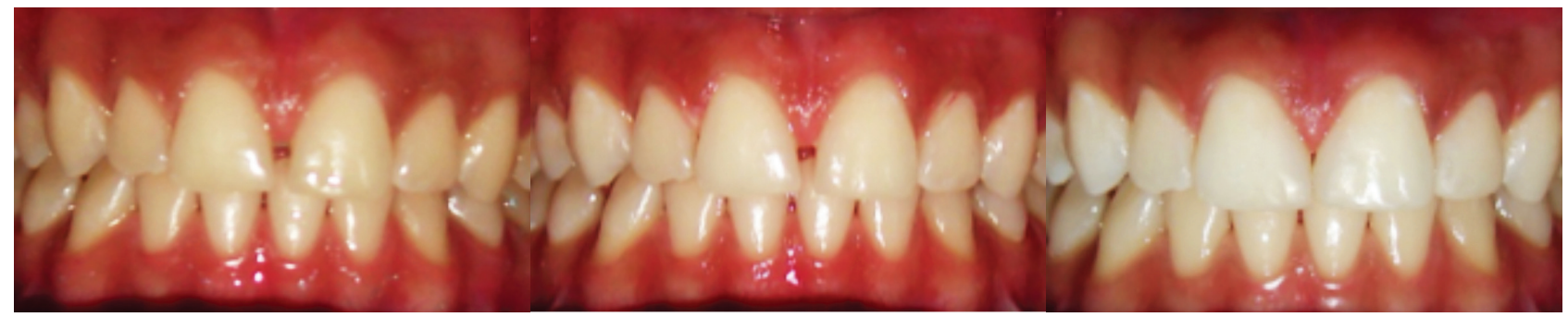

Figure 4 - Evolution of the bleaching treatment of the participant D.

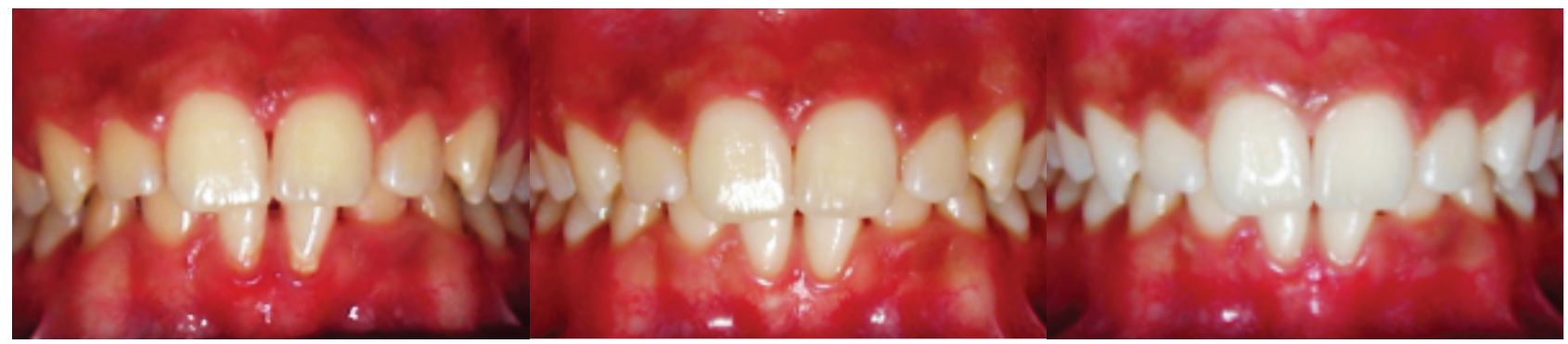


The importance of the smile became even clearer when it was observed that participant expressed in different ways the value given to their smile. An example of this is the following answers to the question "How important is your smile?": "All importance. Because the people used to think me very unfriendly because they did not smile at anyone. Now I'm just smiles ... "- participant A; "It's what changes a person ... it becomes more beautiful ... the appearance changes a lot ... it values." - participant B; "I give a lot of value. I'm always brushing ... "participant D (table 3).

However, despite the reports obtained, it cannot be said that the only cause for these transformations is related to the dental treatment performed. Although some studies point out that changes in the oral health of children and adolescents are capable of repercussion on selfimage and self-esteem interfering directly in their psychosocial context and consequently in their development $[27,28]$ other causes may be related to these cases.

Psychotherapy was performed simultaneously to dental treatment and certainly contributed to these changes, as well as the fact that these individuals no longer feel excluded from society. The humanization of dental care, in many situations, may have become more important than the actual procedure performed. The reception of the participants by the dental professional can help in the evolution of the treatment, facilitating the obtaining of favorable results.

It is undoubtedly possible to assume that, as changes in oral health may manifest as a problem for social life, especially for adolescence, since health and oral aesthetics become important for normal self-image and social interaction [22,32,33], dentists may contribute to the multidisciplinary treatment of young victims of sexual violence. In addition, by collaborating with educational, preventive and therapeutic measures, dentists may help in the social reintegration, as well as in the improvement of their quality of life and selfesteem frequently shaken in these situations.

However, further investigations must be carried out due to the complexity of the subject that involves other factors, such as the socioeconomic condition and the familiar conviviality that may influence the perception of oral health, as well as in the improvement of the self-esteem.

\section{CONCLUSION}

The oral health self-perception of the children and adolescents victims of sexual abuse studied is considered consistent with the presented clinical situation.

It is necessary for dentists to collaborate in the process of multidisciplinary approach victims of sexual abuse given that the result of the dental treatments contributed to improvements regarding self-esteem and oral health selfperception and, possibly, socialization and quality of life.

\section{ACKNOWLEDMENT}

We thank the Dom Hélder Câmara Center (CENDHEC) and the psychologists Isabel Ribeiro da Silva and Heliani Ribeiro, and the SDI BRASIL for, respectively, providing support during the psychological and dental treatments.

\section{REFERENCES}

1. CarlosDM, Pádua EM, Ferriani MGC. Violence against children and adolescents: the perspective of Primary Health Care. Rev Bras Enferm. 2017 ;70(3):511-8.

2. WirtzAL, Alvarez C, Guedes AC, Brumana L, Modvar C, Glass N. Violence against children in Latin America and Caribbean countries: a comprehensive review of national health sector efforts in prevention and response. BMC Public Health. 2016 Sep 22;16(1):1006.

3. Devries KM, Meinck F. Sexual violence against children and adolescents in South Africa: making the invisible visible.Lancet Glob Health. 2018;6(4):e367-e8. 
4. Guedes A, Bott S, Garcia-Moreno C,Colombini M. Bridging the gaps: a global review of intersections of violence against women and violence against children. Glob Health Action. 2016;20(9):31516.

5. Barros LA, Albuquerque MCS, Gomes NP,Riscado JLS, Araújo BRO, Magalhães JRF. The (un)receptive experiences of female rape victims who seek healthcare services. Rev Esc Enferm USP,2015;49(2):193-200.

6. Krug EG, Mercy JA, Dahlberg LL,Zwi AB. The world report on violence and health. Lancet.20020ct5;360(9339):1083-8.

7. Rutherford A, Zwi AB, Grove NJ, ButchartA. Violence: a glossary. Journal of Epidemiology and Community Health. 2007;61(8):676-680.

8. Williams JR, Ghandour RM, Kub JE. Female perpetration of violence in heterosexual intimate relationships: adolescence through adulthood. Trauma, violence \& abuse. 2008;9(4):227-49.

9. Pires ALD, Miyazaki MCOS. Maus-tratos contra crianças e adolescentes: revisão da literatura para profissionais da saúde. Arq Ciênc Saúde. 2005; 12(1): 42-9.

10. Chan KL, Yan E, Brownridge DA, Tiwari A, Fong DY. Childhood sexual abuse associated with dating partner violence and suicidal ideation in a representative household sample in Hong Kong. J Interpers Violence. 2011 Jun;26(9):1763-84

11. Chen LP,Murad MH, Paras ML, et al. Sexual Abuse and Lifetime Diagnosis of Psychiatric Disorders: Systematic Review and Meta-analysis. Mayo Clinic Proceedings. 2010;85(7):618-29.

12. Yüce M, Karabekiro luK, YildirimZ, ahinS, SapmazD, BabadaiZ etal. The Psychiatric Consequences of Child and Adolescent Sexual Abuse. Nöro Psikiyatri Ar ivi. 2015;52(4):393-9

13. Jacobson M. Child Sexual Abuse and the Multidisciplinary Team Approach: Contradictions in Practice, Childhood, Childhood, 2001;8(2):231-50.

14. Werneck MAF.Bucalidade e existência. Ciência e Saúde Coletiva. 2006;11(1):1843.

15. Eriksen HM, Dimitrov V. The human mouth: oral functions in a social complexity perspective. Acta Odontol Scand. 2003;61(3):172-7.

16. Glover E. Significance of Mouth in Psychoanalysis, British Journal of Medical Psychology, 1924; IV:134-55.

17. Ahnallen JM, Suyemoto KL, Carter AS. Relationship between physical appearance, sense of belonging and exclusion, and racial/ethnic selfidentification among multiracial Japanese European Americans. Cultur Divers Ethnic Minor Psychol. 2006 0ct;12(4):673-86.

18. Al Odhayani A, Watson WJ, Watson L. Behavioural consequences of child abuse. Canadian Family Physician. 2013;59(8):831-6.

19. Rosenberg M,Schooler C, Schoenbach C, Rosenberg F.Global self-esteem and specific self-esteem Different concepts, different outcomes. Am Soc Rev. 1995;60(1):141-56.
20. Baumeister RF,Campbell JD, Krueger JI, Vohs KK. Does high self-esteem cause better performance, interpersonal success, happiness, or healthier lifestyles? Psychological Science in the Public Interest. 2003;4:1-44.

21. Kaur P,Singh S, Mathur A, Makkar DK, Aggarwal VP,Batra M et al. Impact of Dental Disorders and its Influence on Self Esteem Levels among Adolescents. JClin Diagn Res. 2017 Apr;11(4):ZC05-ZC08.

22. Silva Júnior IF, Goettem ML, Azevedo MS. - Oral health status of children and adolescents victims of abuse: a literature review, RSB0, 2016;13(2):104-8.

23. Alshammari MS, Alshammari AS, Siddiqui AA, Mirza AJ, Mian RI. Patients' Knowledge and Perceived Barriers toward Replacement of Missing Teeth among Respondents of Hail City, Kingdom of Saudi Arabia. J Contemp Dent Pract. 2018 Jan 1;19(1):86-9.

24. Unfer B, Saliba 0. Avaliação do conhecimento popular e práticas cotidianas em saúde bucal. Rev Saúde Pública. 2000;34(2):190-195.

25. O'Leary TJ, Drake RB, Naylor JE. The plaque control Record. J.Periodontol. 1972;43(1):38

26. Laville C, Dionne J.Das Informações à conclusão. In: _ A Construção do Saber.Porto Alegre:Editora UFMG, 1999; Cap. 8: 197-231.

27. Marques LS, Pordeus IA, Ramos-Jorge ML, Filogônio CA, Filogônio CB, Pereira $\mathrm{LJ}$, etal. Factors associated with the desire of orthodontic treatment among Brazilian adolescents and their parents. BMC Oral Health. 2009;9:34.

28. De Paula DF, Santos NCM, SilvaET, Nunes MF,Leles CR. Psychosocial impact of dental esthetics on quality of life in adolescents: association with malocclusion, self-image, and oral health-related issues. Angle Orthod. 2009;79:1188-93.

29. World Health Organization.Constitution. The Preamble of the Constitution of the World Health Organization. Bulletin of the World Health Organization. 1948;80(12):982.

30. Manchanda K, Sampath N, Sarkar AD. Evaluating the effectiveness of oral health education program among mothers with 6-18 months children in prevention of early childhood caries. Contemporary Clinical Dentistry. 2014;5(4):478-83.

31. Shah N, Mathur VP, Kathuria V, Gupta T.Effectiveness of an educational video in improving oral health knowledge in a hospital setting. Indian Journal of Dentistry.2016;7(2):70-5.

32. Afroz S, Rathi S, Rajput G, Rahman SA. Dental Esthetics and Its Impact on Psycho-Social Well-Being and Dental Self Confidence: A Campus Based Survey of North Indian University Students. The Journal of the Indian Prosthodontic Society. 2013;13(4):455-60.

33. Davis LG, Ashworth PD, Sprigs LS. Psychological effects of aesthetic dental treatment.JDent. 1998;26(7):547-54.

\section{Claudio Heliomar Vicente da Silva}

(Corresponding address)

UFPE - Departamento de Prótese e Cirurgia Buco-Facial

Avenida Prof. Moraes Rego, S/N, CDU. Recife - Pernambuco

- Brasil. CEP: 50670-901

Email: claudio rec@hotmail.com

Date submitted: 2017 Nov 19

Phone number: + 5581 2126-8440

Accept submission: 2018 Apr 17 